\title{
EFFECT OF FUEL INJECTOR HOLE DIAMETER AND INJECTION TIMING ON THE MIXTURE FORMATION IN A GDI ENGINE - A CFD STUDY
}

\author{
PRIYANKA D. JADHAV \& J. M. MALLIKARJUNA \\ Internal Combustion Engine Laboratory, Department of Mechanical Engineering, \\ Indian Institute of Technology Madras, Chennai.
}

\begin{abstract}
Performance and emission characteristics of a gasoline direct injection (GDI) engine are mainly influenced by the in-cylinder mixture preparation. However, in these engines, mixture formation depends upon many factors viz., fuel injection strategy and parameters, mode of operation, engine geometry, etc. Therefore, understanding the mixture formation, under various engine operating conditions and fuel system configurations, is very much essential. In this study, an attempt has been made to understand the effect of fuel injector-hole diameter and fuel injection timing on the mixture formation in a four-stroke, wall-guided GDI engine using computational fluid dynamics (CFD) analysis. The CFD simulations are carried out from inlet valve opening (IVO) to exhaust valve opening (EVO) period using the CONVERGE. The CFD models used are validated with the available data from the literature. The engine considered has a compression ratio (CR) of 11.5. All the CFD simulations are carried out at the engine speed of $2000 \mathrm{rev} / \mathrm{min}$. Three fuel injector-hole diameters viz., 0.1, 0.14 and $0.18 \mathrm{~mm}$ and three fuel injection timings viz., 605, 620 and 635 crank angle degree (CAD) are considered for the analysis. The mixture formation is analyzed in the vicinity of the spark plug and at other parts of the combustion chamber. From the results, it is found that higher nozzle-hole diameter yielded very rich mixture zones near spark plug. Also, lower nozzle-hole diameter and retarded fuel injection timing showed higher indicated mean effective pressure (IMEP).

Keywords: combustion, fuel injection strategies, GDI engine, mixture stratification.
\end{abstract}

\section{INTRODUCTION}

Currently, gasoline direct injection (GDI) engines are preferred over the conventional port fuel injection (PFI) engines, because of better performance and emission characteristics. GDI engines are operated at two modes: homogeneous and stratified. In the stratification mode, engine performance and emissions are mainly affected by the in-cylinder mixture formation at the time of ignition [1]. But, the mixture stratification depends upon many factors viz., engine geometry, fuel injection strategy, engine operating conditions, etc., [2, 3]. Hence, it is important to study the mixture stratification inside the combustion chamber to optimize engine and operating parameters for better performance and emissions characteristics.

Previously, Krishna and Mallikarjuna [4] studied the effect of engine parameters on the mixture stratification in a wall-guided GDI engine using CFD analysis. They developed a parameter called 'stratification index' to quantify the mixture stratification. The simulations were carried out at the engine speeds varying from 2000 to $4000 \mathrm{rev} / \mathrm{min}$., with CRs of 10.5 , 11.5 and 12.5 and inlet air pressures of 1, 1.2 and 1.4 bar. Their results showed that the mixture stratification in a wall-guided engine varied significantly with the engine speed and inlet air pressure, whereas it was not much affected by CR. Costa et al. [5] analyzed mixture formation and early flame development in a GDI engine through numerical simulations and ultraviolet digital imaging under various fuel injection and ignition timings. They conducted experiments, in a four-valve, single-cylinder wall-guided GDI engine, at full-throttle operation with the CR of 10.5 , the engine speed of $2000 \mathrm{rev} / \mathrm{min}$., the fuel injection pressure of $100 \mathrm{bar}$ and the 
equivalence ratio of $1.1 \pm 1 \%$. They reported that the early fuel injection resulted in the formation of homogeneous mixture which led to stable combustion. Also, the stratified mixture increased cycle-by-cycle variations. Li et al. [6] investigated experimentally the mixture formation under split fuel injection in a GDI engine. The laser absorption and scattering (LAS) technique was used to measure the concentration of liquid and vapor phase sprays. The laser-induced fluorescence-particle image velocimetry (LIF-PIV) technique was used for analyzing the fuel spray and the flow of ambient air. The tests were carried out at various ambient pressures and temperatures, fuel injection pressures and total fuel quantities. They reported that an optimum combustion in a GDI engine could be achieved by using two fuel injection pulses. Costa et al. [7] investigated experimentally the mixture preparation and combustion, in an optically accessed turbocharged GDI engine, under various fuel injection pressures, and stoichiometric and lean mixture conditions. Their results showed that the stoichiometric mixture resulted in higher heat release and NO emissions, compared to that of lean mixture. Also, increasing fuel injection pressure and advancing the ignition timing improved power output and cyclic variations and reduced $\mathrm{CO}$ and soot emissions. Costa et al. [8] analyzed experimentally and numerically the effect of split fuel injection on engine power output and emissions in a four-valve single-cylinder turbocharged optical GDI engine. The tests were carried out at the engine speed of $2000 \mathrm{rev} / \mathrm{min}$., fuel injection pressure of 100 bar, full-throttle conditions and the equivalence ratio of 1.1. Fuel injection was done in two stages during suction and compression strokes with equal mass of fuel. They reported that the heat release rate could be enhanced by the proper choice of spark and fuel injection timings.

From the above discussion, it is understood that, the mixture formation, in a GDI engine, is influenced significantly by many engine conditions. Also, in a wall-guided GDI engine, it mainly depends upon piston shape, engine speed, fuel injection strategy, etc. However, the evaluation of simultaneous effect of fuel injection strategy and nozzle geometry on mixture formation is rarely reported in the literature. Therefore, the present CFD analysis investigates the effect of fuel injection timings and nozzle-hole diameter on the mixture formation in a wall guided GDI engine.

\section{CFD METHODOLOGY}

\subsection{Engine specifications}

The present study considers a four-valve, four-stroke, pentroof head, single-cylinder wall guided GDI engine. Table 1 shows the engine specifications used in this study [5].

Table 1: Engine specifications (Costa et al., [5]).

\begin{tabular}{ll}
\hline Stroke $(\mathrm{mm})$ & 79 \\
Bore $(\mathrm{mm})$ & 81.3 \\
Connecting rod length $(\mathrm{mm})$ & 143 \\
Compression ratio & $10.6: 1$ \\
Number of valves & 4 \\
Inlet valve opening (IVO) & 3 CAD before TDC \\
Inlet valve closing (IVC) & 36 CAD after BDC \\
Exhaust valve opening (EVO) & 27 CAD before TDC \\
Exhaust valve closing (EVC) & 0 CAD after TDC \\
\hline
\end{tabular}




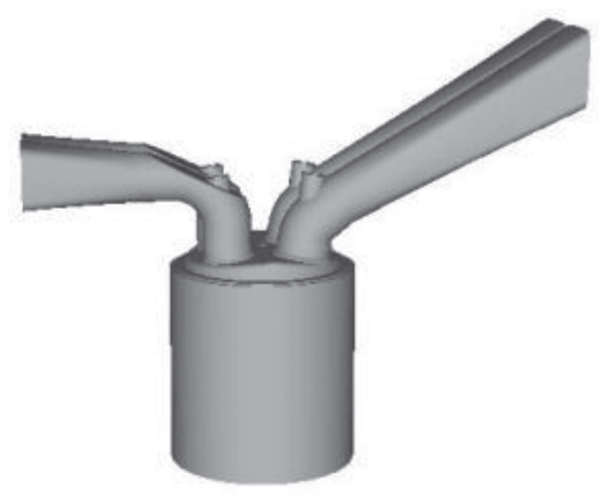

Figure 1: Engine computational domain.

\subsection{Geometric Modelling and Meshing}

The engine computational domain is modelled using the PTC-CREO as shown in Fig. 1. The full cycle CFD simulations are carried out using the CONVERGE. In the CONVERGE, the complex geometrical intersections are represented using a modified cut-cell Cartesian grid generation method. Two million cells are generated with the base mesh size of $4 \mathrm{~mm}$. The velocity and temperature gradients during valve motion, fuel spray and combustion processes are captured using adaptive mesh refinement using maximum and minimum mesh sizes of 1 and $0.125 \mathrm{~mm}$, respectively.

\subsection{Boundary conditions}

The intake pressure of 1 bar and intake temperature of $310 \mathrm{~K}$ are used. Exhaust gas is assumed to be delivered at the atmospheric pressure and at the temperature of $366 \mathrm{~K}$. The engine speed of $2000 \mathrm{rev} / \mathrm{min}$., compression ratio of 11.5 and equivalence ratio of $0.75 \pm 0.05$ are kept constant throughout the analysis.

\subsection{CFD models considered}

In-cylinder incompressible flow modelling considers the following governing equation [9].

$$
\frac{\partial(\rho \varphi)}{\partial t}+\operatorname{div}(\rho \varphi u)=\operatorname{div}(\Gamma \operatorname{grad} \varphi)+S_{\varphi}
$$

The RNG k- $\varepsilon$ turbulence model is used to capture the in-cylinder turbulent flow characteristics $[10,11]$. The macroscopic fuel spray characteristics are predicted using the KH-RT spray breakup model [12]. Fuel spray wall impingement is predicted by the model developed by O'Rourke and Amsden [13, 14]. Table 2 summarises the other CFD models used in the present study.

\subsection{Validation of the CFD models}

The CFD models used in the present study are validated by comparing the CFD predicted in-cylinder pressures with that of the experimental results of Costa et al. [5]. Figure 2 shows 
Table 2: CFD models used.

Spray break-up model

Spray evaporation model

Spray collision model

Spray wall impingement model

Turbulence model

Combustion model
Kelvin-Helmholtz and Rayleigh-Taylor (KH-RT)

Frossling model

O'Rourke

O'Rourke and Amsden

RNG k- $\varepsilon$

Detailed chemical kinetics SAGE

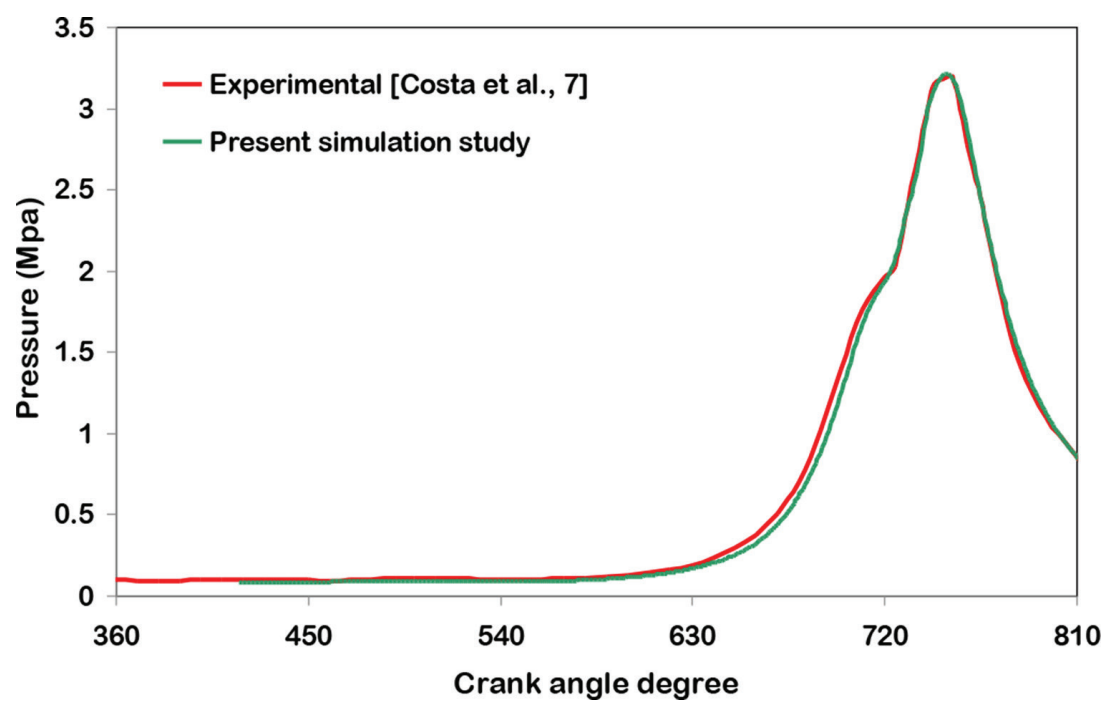

Figure 2: Comparison of in-cylinder pressures.

the comparison of the in-cylinder pressure traces obtained by Costa et al. [5] and that of the present study at the engine speed of $2000 \mathrm{rev} / \mathrm{min}$., and the CR of 10.6. Both the results are in reasonably good agreement.

In addition, for the similar engine and the CFD models, Krishna and Mallikarjuna [4] predicted the spatial distribution of ER, at the time of ignition (710 CAD) using CFD analysis and compared it with that of the Costa et al. [5], as shown in Fig. 3. From Fig. 3, it is seen that, the ER distribution plots from the previous studies $[4,5]$ are in reasonably good agreement. Therefore, the CFD models can be used confidently for further CFD simulations.

\subsection{Operating conditions}

The effect of nozzle-hole diameter and start of injection (SOI) on in-cylinder pressure, in-cylinder mean temperature, heat release rate, etc., is investigated at $2000 \mathrm{rev} / \mathrm{min}$., and at equivalence ratio of $0.75 \pm 0.05$. The compression ratio of 11.5 , the fuel injection pressure of 90 bar and the spark timing at $710 \mathrm{CAD}$ are kept constant throughout the study. The three nozzle-hole diameters of $0.1,0.14$ and $0.18 \mathrm{~mm}$ are used along with the SOIs of 605, 620 and 


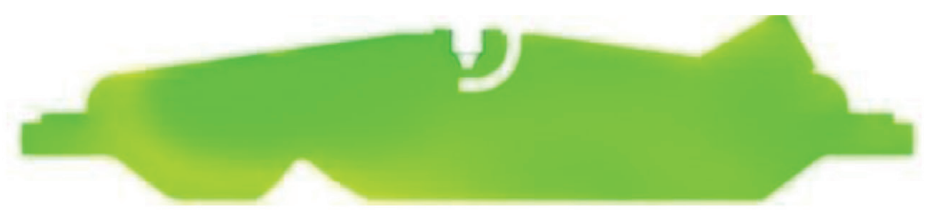

(a) From the CFD analysis of Krishna and Mallikarjuna [4]

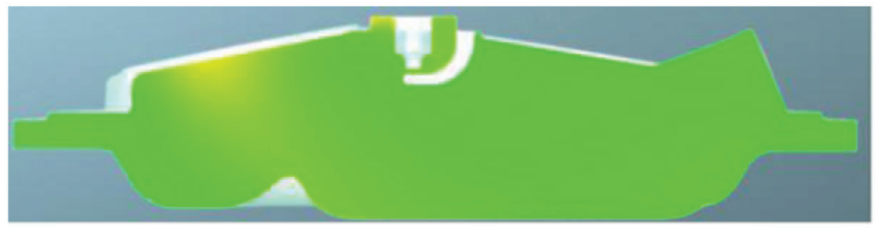

(b) From the CFD analysis of Costa et al. [5]

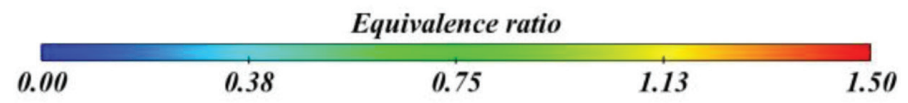

Figure 3: Comparison of ER distribution on the vertical central plane at the time of spark.

$635 \mathrm{CAD}$. For comparison of results, the nozzle-hole diameter of $0.1 \mathrm{~mm}$ and the SOI of 605 $\mathrm{CAD}$ are considered as the basis.

\section{RESULTS AND DISCUSSION}

3.1 Effect of nozzle-hole diameter and fuel injection timing on in-cylinder pressure

Figure 4(a) shows the comparison of in-cylinder pressures at various fuel injector nozzle-hole diameters, at the SOI of 605 CAD. From Fig. 4(a), it is seen that, as the nozzle-hole diameter increases, the rate of pressure rise (slope of the curve) and the peak in-cylinder pressure reduces. This is because, when the nozzle-hole diameter increases, the fuel droplet size increases and thereby fuel atomization reduces, resulting in poor air-fuel mixing and combustion. Therefore, the nozzle-hole diameter of $0.1 \mathrm{~mm}$ is considered as the optimum one and used for the further analysis. From Fig. 4(a), it is found that, at the nozzle-hole diameters of 0.14 and $0.18 \mathrm{~mm}$, in-cylinder peak pressures decrease by about 14 and $22.3 \%$ respectively, compared to that of the nozzle-hole diameter of $0.1 \mathrm{~mm}$.

Figure 4(b) shows the comparison of in-cylinder pressures for various SOIs and the nozzle-hole diameter of $0.1 \mathrm{~mm}$. From Fig. 4(b), it is seen that, for the nozzle-hole diameter of $0.1 \mathrm{~mm}$, the peak in-cylinder pressure and rate of pressure rise are higher at a particular SOI (can be considered as the optimum). When the SOI is retarded or advanced from the optimum SOI, both the peak in-cylinder pressure and rate of pressure rise reduce. From Fig. 4(b), it is found 


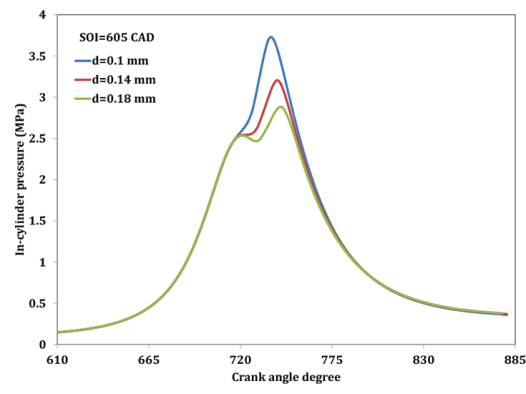

(a) Various nozzle-hole diameters

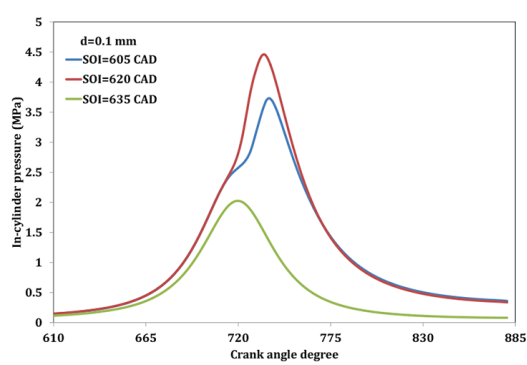

(b) Various fuel injection timings

Figure 4: Comparison of in-cylinder pressures.

that, at the optimum SOI of $620 \mathrm{CAD}$, the in-cylinder peak pressure increases by about $19.6 \%$ and at the SOI of 635 CAD it decreases by about $45.8 \%$, compared to that of the SOI of 605 CAD.

3.2 Effect of nozzle-hole diameter and fuel injection timing on mean in-cylinder temperature

Figure 5(a) shows the comparison of mean in-cylinder temperatures for various fuel injector nozzle-hole diameters, at the SOI of 605 CAD. From Fig. 5(a), it is seen that, at the SOI of $605 \mathrm{CAD}$, with the increase in nozzle-hole diameter, the in-cylinder mean temperature reduces. This is again because of poor fuel atomization at higher nozzle-hole diameters, which results in poor fuel evaporation, mixing and combustion. From Fig. 5(a), it is found that, the peak in-cylinder temperature decreases by about 3.3 and $6.5 \%$, for the nozzle-hole diameters of 0.14 and $0.18 \mathrm{~mm}$, respectively, compared to that of nozzle-hole diameter of 0.1 mm.

Figure 5(b) shows the comparison of mean in-cylinder temperatures for various SOIs and the nozzle-hole diameter of $0.1 \mathrm{~mm}$. From Fig. 5(b), it is seen that the in-cylinder temperature is more at the optimum SOI (620 CAD), similar to the trend of in-cylinder pressure, compared to

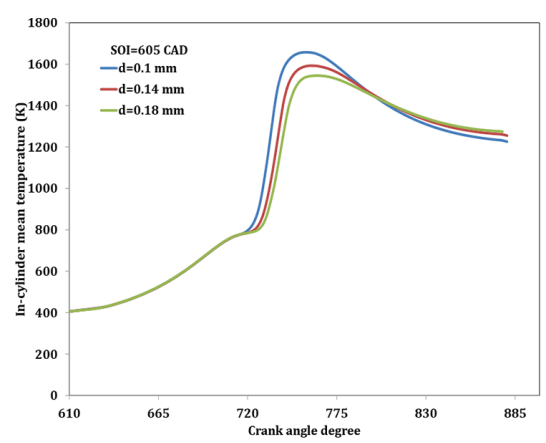

(a) Various nozzle-hole diameters

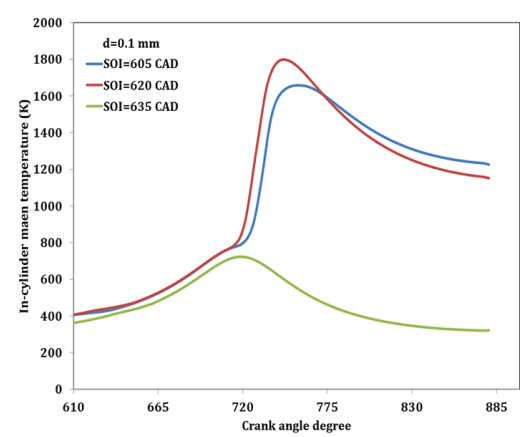

(b) Various fuel injection timings

Figure 5: Comparison of mean in-cylinder temperatures. 
that of the SOI of 605 CAD. However, at the SOI of 635 CAD, there is no combustion. This is because, when the SOI is more retarded, the mixture at vicinity of the spark plug may not be in the combustible range, which due to less time available for the mixture formation. From Fig. 5(b), it is found that at the SOI of $620 \mathrm{CAD}$, peak in-cylinder temperature increases by about $9 \%$, whereas at the SOI of 635 CAD it decreases by about $56.3 \%$, compared to that of the SOI of 605 CAD.

\subsection{Effect of nozzle-hole diameter and fuel injection timing on heat release rate}

Figure 6(a) shows the comparison of heat release rates for various fuel injector nozzle-hole diameters, at the SOI of 605 CAD. From Fig. 6(a), it is seen that at the SOI of 605 CAD, with the increase in the nozzle-hole diameter, the heat release rate reduces. This is because, as the nozzle-hole diameter increases, the fuel droplet size increases resulting in poor atomization and combustion, which leads to reduced heat release rate. From Fig. 6(a), it is found that the peak heat release rate decreases by about 6.6 and $13.1 \%$, for the nozzle-hole diameters of 0.14 and $0.18 \mathrm{~mm}$, respectively, compared to that of nozzle-hole diameter of $0.1 \mathrm{~mm}$.

Figure 6(b) shows the comparison of heat release rates for various SOIs, at the nozzle-hole diameter of $0.1 \mathrm{~mm}$. From Fig. 6(b), it is seen that the heat release rate is more at the optimum SOI (620 CAD). At the SOI of $635 \mathrm{CAD}$, as mentioned earlier, there may not be combustible mixture near the spark plug, leading to no combustion. From Fig. 6(b), it is found that at the $\mathrm{SOI}$ of $620 \mathrm{CAD}$, heat release rate increases by about $7.1 \%$, compared to that of the SOI of 605 CAD.

\subsection{Effect of nozzle-hole diameter and fuel injection timing on stratification index}

Here, the mixture distribution in the engine combustion chamber is expressed quantitatively, using a parameter called stratification index (SI) [4]. Here, the SI equal to 1 refers to an ideally stratified mixture (representing equivalence ratio of the mixture near the spark plug is in the combustible range and decreases away from the spark plug). The SI less than 1 represents improperly stratified mixture (i.e., a lean mixture in the vicinity of the spark plug), whereas the SI greater than 1 represents a very rich mixture in the vicinity of the spark plug. Hence, an optimum combustion needs the mixture distribution that has the SI close to 1 .

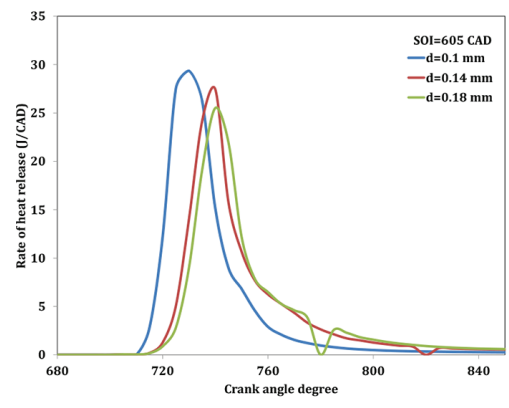

(a) Various nozzle-hole diameters

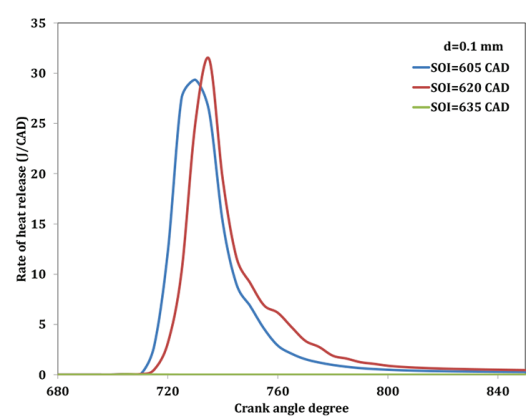

(b) Various fuel injection timings

Figure 6: Comparison of heat release rates. 


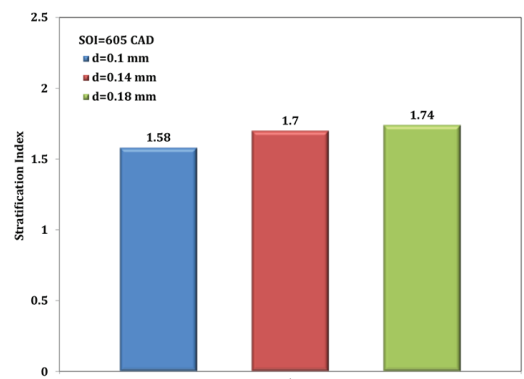

(a) Various nozzle-hole diameters

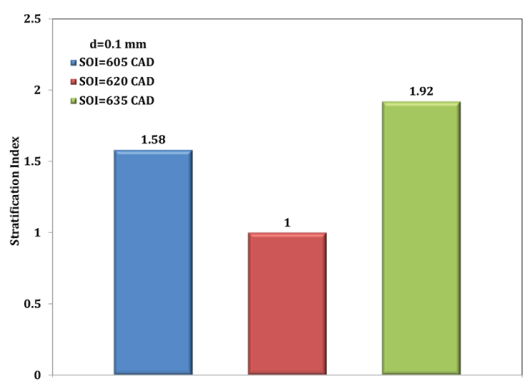

(b) Various fuel injection timings

Figure 7: Comparison of stratification indices.

Figure 7(a) shows the comparison SI at various fuel injector nozzle-hole diameters and the SOI of 605 CAD. From Fig. 7(a), it is seen that as the nozzle-hole diameter increases, the SI increases. It means that the degree of richness of the mixture near the spark plug increases with the increase in nozzle-hole diameter. From Fig. 7(a), it is seen that for the nozzle-hole diameters of 0.14 and $0.18 \mathrm{~mm}$, SI is about 1.7 and 1.74, respectively. Therefore, large nozzlehole diameter is not advisable.

Figure 7(b) shows the comparison of SIs for various SOIs. From Fig. 7(b), it is seen that for the nozzle-hole diameter of $0.1 \mathrm{~mm}$ at the SOI of 605 , the SI is about 1.58 which represents that the mixture is rich near the spark plug. At the SOI of $620 \mathrm{CAD}$, the SI is equal to 1 which represents that the mixture is properly stratified. At the SOI of 635, the SI is about 1.92 which represents the too rich mixture at the spark plug location and therefore no ignition and combustion. The SOI of 620 which results in the formation of a properly stratified mixture exhibits a high peak in-cylinder pressure and temperature compared to all the other conditions considered. From Fig. 7(b), it is found that at the SOI of $620 \mathrm{CAD}$, the SI decreases by about 0.58 and at the SOI of 635 , it increases by about 0.34 compared to that of the SOI of 605 CAD.

\subsection{Effect of nozzle-hole diameter and fuel injection timing on IMEP}

Figure 8(a) shows the comparison IMEP at various fuel injector nozzle-hole diameters and the SOI of 605 CAD. From Fig. 8(a), it is seen that, as the nozzle-hole diameter increases, the

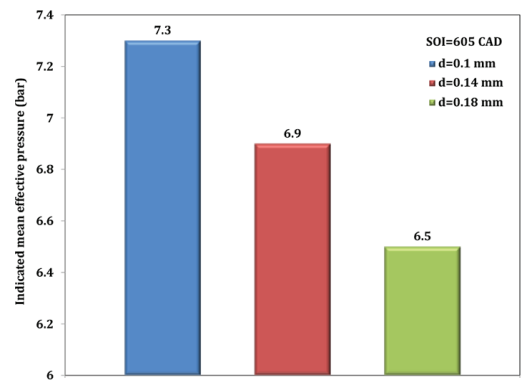

(a) Nozzle-hole diameter

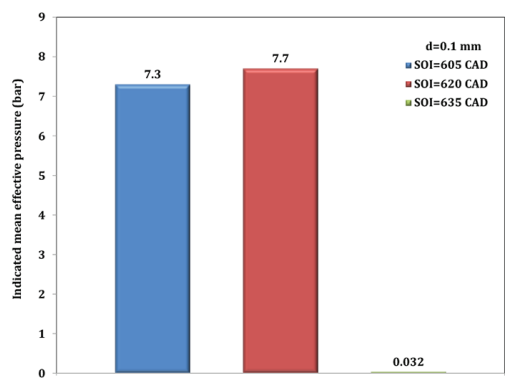

(b) Fuel injection timing

Figure 8: Comparison of IMEPs. 
IMEP reduces. This is because, as discussed earlier, when the nozzle-hole diameter increases, fuel droplet size increases leading to poor atomization, mixing and combustion, and thereby the in-cylinder pressure decreases during the entire cycle and consequently reducing the engine IMEP. From Fig. 8(a), it is found that, at the nozzle-hole diameters of 0.14 and 0.18 $\mathrm{mm}$, the IMEP decreased by about 5.5 and $10.95 \%$, respectively, compared to that of the nozzle-hole diameter of $0.1 \mathrm{~mm}$.

Figure 8(b) shows the comparison of the IMEP for various SOIs and the nozzle-hole diameter of $0.1 \mathrm{~mm}$. From Fig. 8(b), it is seen that for the nozzle-hole diameter of $0.1 \mathrm{~mm}$, at the optimum SOI of 620, the IMEP is higher, compared to that of the SOI of 605 CAD. Further retardation of the SOI to $635 \mathrm{CAD}$, resulted in no combustion. From Fig. 8(b), it is found that at the optimum SOI of $620 \mathrm{CAD}$, the IMEP increases by about $5.5 \%$ and it is insignificant at the SOI of 635 CAD.

\subsection{Effect of nozzle-hole diameter and fuel injection timing on NOx emissions}

Figure 9(a) shows the comparison of NOx emissions, at various fuel injector nozzle-hole diameters and the SOI of 605 CAD. From Fig. 9(a), it is seen that as the nozzle-hole diameter increases, the NOx emissions reduce. This is because of the reduction in in-cylinder temperature at higher nozzle-hole diameters (Fig. 5(a)). From Fig. 9(a), it is found that at the nozzle-hole diameters of 0.14 and $0.18 \mathrm{~mm}$, the NOx emissions decrease by about 21 and $33 \%$, respectively, compared to that of the nozzle-hole diameter of $0.1 \mathrm{~mm}$.

Figure 9(b) shows the comparison NOx emissions for various SOIs and the nozzle-hole diameter of $0.1 \mathrm{~mm}$. From Fig. 9(b), it is seen that at the nozzle-hole diameter of $0.1 \mathrm{~mm}$, the NOx emissions are higher at the SOI of $620 \mathrm{CAD}$, where the in-cylinder temperatures are higher. At other two SOIs, the NOx emissions are lower because of lower in-cylinder temperatures (Fig. 5(b)). From Fig. 9(b), it is found that at the SOI of 620 CAD, the NOx emissions increase by about $56.25 \%$, compared to that of the SOI of 605 CAD. Off course at the SOI of 635 $\mathrm{CAD}$, there exist no NOx emissions because there is no combustion.

\subsection{Effect of nozzle-hole diameter and fuel injection timing on CO emissions}

Figure 10(a) shows the comparison CO emissions, at various fuel injector nozzle-hole diameters and the SOI of 605 CAD. From Fig. 10(a), it is seen that, as the nozzle-hole diameter increases,

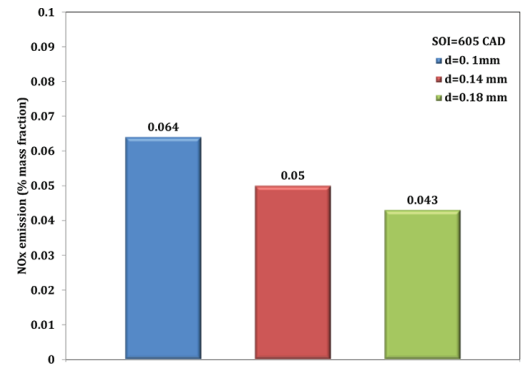

(a) Various nozzle-hole diameters

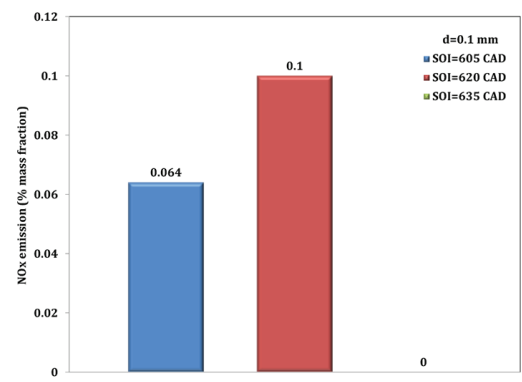

(b) Various fuel injection timings

Figure 9: Comparison of NOx emissions. 


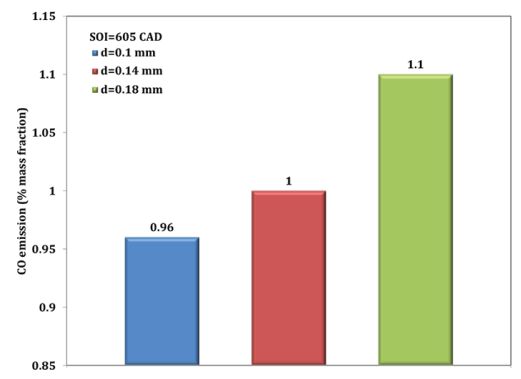

(a) Nozzle-hole diameter

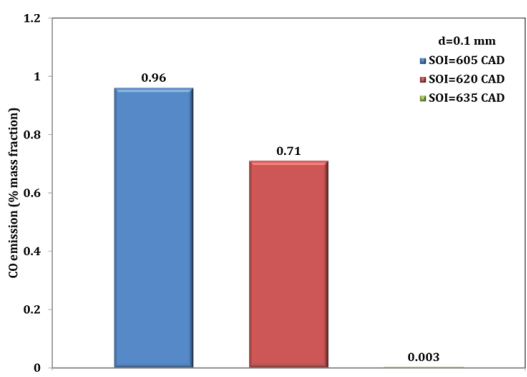

(b) Fuel injection timing

Figure 10: Comparison of CO emissions.

the $\mathrm{CO}$ emissions increase. This is because of local rich zones occurring due to poor mixing as a result of lower atomization with the increase in nozzle-hole diameter. From Fig. 10(a), it is found that at the nozzle-hole diameters of 0.14 and $0.18 \mathrm{~mm}, \mathrm{CO}$ emissions increase by about 4 and $14.6 \%$, respectively, compared to that of the nozzle-hole diameter of $0.1 \mathrm{~mm}$.

Figure 10(b) shows the comparison of CO emissions, for various SOIs and at the nozzlehole diameter of $0.1 \mathrm{~mm}$. From Fig. 10(b), it is seen that for the nozzle-hole diameter of 0.1 $\mathrm{mm}$, the $\mathrm{CO}$ emissions decrease at the SOI of $620 \mathrm{CAD}$, whereas no $\mathrm{CO}$ emissions occur, at the SOI of 635 CAD due to no combustion. From Fig. 10(b), it is found that at the SOI of $620 \mathrm{CAD}$, the $\mathrm{CO}$ emissions decrease by about $26 \%$, compared to that of the SOI of 605 CAD.

\subsection{Effect of nozzle-hole diameter and fuel injection timing on $\mathrm{HC}$ emissions}

Figure 11(a) shows the comparison of $\mathrm{HC}$ emissions at various fuel injector nozzle-hole diameters and the SOI of 605 CAD. From Fig. 11(a), it is seen that as the nozzle-hole diameter increases, the HC emissions increase. This is because of improper fuel evaporation and mixing with air at large nozzle-hole diameter due to poor atomization as mentioned earlier. From Fig. 11(a), it is found that at the nozzle-hole diameters of 0.14 and $0.18 \mathrm{~mm}$, the HC

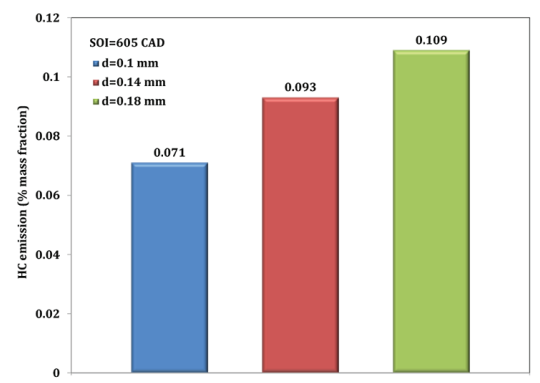

(a) Various nozzle-hole diameters

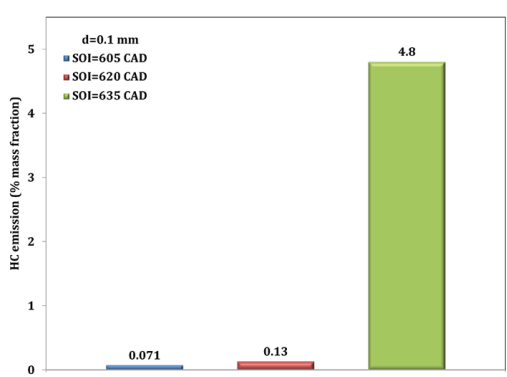

(b) Various fuel injection timings

Figure 11: Comparison of $\mathrm{HC}$ emissions. 
emissions increase by about 31 and $53.5 \%$, respectively, compared to that of the nozzle-hole diameter of $0.1 \mathrm{~mm}$.

Figure 11(b) shows the comparison of HC emissions for various SOIs. From Fig. 11(b), it is seen that for the nozzle-hole diameter of $0.1 \mathrm{~mm}$, the $\mathrm{HC}$ emissions increase with the retarded of SOI. This again because of less time available for fuel evaporation and mixing with air, at the retarded SOI. From Fig. 11(b), it is found that at the SOI of 620 CAD, the HC emissions increase by about $83 \%$, compared to that of the SOI of 605 CAD. Also, high HC emissions at the SOI of $635 \mathrm{CAD}$ show the emission of unburnt fuel due to no combustion.

\section{CONCLUSIONS}

From the analysis of results, the following conclusions are drawn:

- At the SOI of $620 \mathrm{CAD}$, peak in-cylinder pressure increased by about $19.6 \%$, and at the SOI of 635 CAD, it decreased by about $45.8 \%$ compared to that of the SOI of 605 CAD. At the nozzle-hole diameter of 0.14 and $0.18 \mathrm{~mm}$, peak in-cylinder pressure decreased by about 14 and $22.3 \%$, respectively, compared to that of the nozzle-hole diameter of $0.1 \mathrm{~mm}$.

- At the SOI of $620 \mathrm{CAD}$, the peak heat release rate increased by about $7.1 \%$ as compared to that of the SOI of 605 CAD. At the nozzle-hole diameter of 0.14 and $0.18 \mathrm{~mm}$, it decreased by 9.7 and $14.5 \%$, respectively, compared to that of the nozzle-hole diameter of $0.1 \mathrm{~mm}$.

- At the SOI of $620 \mathrm{CAD}$, the IMEP increased by about $5.5 \%$, compared to that of the SOI of $605 \mathrm{CAD}$. At the nozzle-hole diameter of 0.14 and $0.18 \mathrm{~mm}$, the IMEP decreased by about 5.5 and $11 \%$, respectively, compared to that of the nozzle-hole diameter of $0.1 \mathrm{~mm}$.

- At the SOI of 620 CAD, the NOx emissions increased by about $56.3 \%$, compared to that of the SOI of 605 CAD. At the nozzle-hole diameter of 0.14 and $0.18 \mathrm{~mm}$, the NOx emissions decreased by about 22 and $33 \%$, respectively, compared to that of the nozzle hole diameter of $0.1 \mathrm{~mm}$.

- At the SOI of $620 \mathrm{CAD}$, the CO emissions decreased by about $26 \%$, compared to that of the SOI of 605 CAD. At the nozzle-hole diameter of 0.14 and $0.18 \mathrm{~mm}$, the CO emissions increased by about 4.2 and $14.6 \%$, respectively, compared to that of the nozzle-hole diameter of $0.1 \mathrm{~mm}$.

- At the SOI of $620 \mathrm{CAD}$, the HC emissions increased by about $83 \%$, compared to that of the SOI of 605 CAD. At the nozzle-hole diameter of 0.14 and $0.18 \mathrm{~mm}$, the HC emissions increased by about 31 and $53.5 \%$, respectively, compared to that of at nozzle-hole diameter of $0.1 \mathrm{~mm}$.

- Finally, it is concluded that, the nozzle-hole diameter of $0.1 \mathrm{~mm}$ and the SOI of $620 \mathrm{CAD}$ is the optimum configuration, to have a properly stratified mixture and to improve the indicated mean effective pressure, in the wall guided single-cylinder GDI engine.

\section{REFERENCES}

[1] Zhao, F.Q., Lai, M.C. \& Harrington, D.L., Automotive spark-ignited direct-injection gasoline engines. Progress in Energy and Combustion Science, 25, pp. 437-562, 1999. https://doi.org/10.1016/s0360-1285(99)00004-0

[2] Ganesan, V., Internal Combustion Engines. Tata McGraw-Hill Publishing Company Limited, New Delhi, 2003.

[3] Heywood, J.B., Internal Combustion Engine Fundamentals. McGraw-Hill Higher Education, New Delhi, 1988. 
[4] Addepalli, S.K. \& Mallikarjuna, J.M., Effect of engine performance on mixture stratification in a wall guided GDI engine: a quantitative CFD analysis. SAE International Journal of Commercial Vehicles, 10, pp. 562-571, 2017. https://doi.org/10.4271/2017-01-0570

[5] Costa, M., Marchitto, L., Merola, S.S. \& Sorge, U., Study of mixture formation and early flame development in a research GDI engine through numerical simulation and UV-digital imaging. Energy, 77, pp. 88-96, 2014. https://doi.org/10.1016/j.energy.2014.04.114

[6] Li, T., Nishida, K., Zhang, Y. \& Hiroyasu, H., Effect of split injection on stratified charge formation of direct injection spark ignition engines. International Journal of Engine Research, 8, pp. 205-219, 2007. https://doi.org/10.1243/14680874jer02106

[7] Costa, M., Catapano, F., Sementaa, P., Sorge, U. \& Vaglieco, B.M., Mixture preparation and combustion in a GDI engine under stoichiometric or lean charge: an experimental and numerical study on an optically accessible engine. Applied Energy, 180, pp. 86-103, 2016. https://doi.org/10.1016/j.apenergy.2016.07.089

[8] Costa, M., Sorge, U., Merola, S., Irimescu, A., La Villetta, M. \& Rocco, V., Split injection in a homogeneous stratified gasoline direct injection engine for high combustion efficiency and low pollutants emission. Energy, 117, pp. 405-415, 2016. https://doi.org/10.1016/j.energy.2016.03.065

[9] Krishna, A., Mallikarjuna, J. M., Davinder, K. \& Ramachandra Babu, Y., In-cylinder flow analysis in a two-stroke engine - A comparison of different turbulence models using CFD (SAE Technical Paper, 2013-01-1085), 2013. https://doi.org/10.4271/2013-01-1085

[10] Addepalli, S.K., Mallikarjuna, J.M. \& Davinder, K., Effect of engine parameters on in-cylinder flows in a two-stroke gasoline direct injection engine. Applied Energy, 176, pp. 282-294, 2000. https://doi.org/10.1016/j.apenergy.2016.05.067

[11] Yakhot, V. \& Orszag, S.A., Renormalization group analysis of turbulence. I. basic theory. Journal of Scientific Computing, 1, pp. 3-51, 1986. https://doi.org/10.1007/bf01061452

[12] Reitz, R.D., Modeling atomization processes in high-pressure vaporizing sprays. Atomisation and Spray Technology, 3, pp. 309-337, 1987.

[13] O'Rourke, P.J. \& Amsden, A.A., A particle numerical model for wall film dynamics in port-injected engines (SAE Technical Paper, 961961), 1996.

[14] O'Rourke, P. J. \& Amsden, A., A spray/wall interaction submodel for the KIVA-3 wall film model (SAE Technical Paper, 2000-01-0271), 2000. 